\title{
Cardiopulmonary Responses during Arm Work on Land and in a Water Environment of Nonambulatory, Spinal Cord Impaired Individuals ${ }^{\star}$
}

\author{
Patrick DiRocco, Ph.D., ${ }^{1}$ Akio Hashimoto, M.S., ${ }^{2}$ Ivan Daskalovic, \\ Ph.D. ${ }^{3}$ and Ed Langbein, M.S. ${ }^{4}$ \\ ${ }^{1}$ Department of Physical Education, University of Maryland, College Park, MD., \\ U.S.A., ${ }^{2}$ Biotron, University of Wisconsin, Madison, WI, U.S.A., ${ }^{3}$ Navel \\ Medical Hyperbaric Institute, P.O. Box 8040, Haifa, Israel and ${ }^{4}$ Department \\ of Physical Education, George Williams College, Downers Grove, IL., U.S.A.
}

\section{Summary}

Six handicapped and six nonhandicapped subjects were given exercise tolerance tests on land and in a water environment. The subjects exercised with their arms only and had their cardiopulmonary performance evaluated. Based upon the results observed in this study, it appears that nonambulatory individuals with low fitness levels were able to experience greater cardiopulmonary work outputs when exercising in a water environment. The less severely handicapped individuals displayed similar patterns to those observed in the NH subjects (i.e., no observable pattern) and thus, may not receive as great a benefit as the more severely handicapped. The water environment appears to improve venous return, cardiac output and lung ventilation, which assists the $H$ subjects to be more efficient during exercise.

Key words: Spinal cord paralysed; Cardiopulmonary responses.

The physical work-capacity of nonambulatory individuals has received increased attention during the past decade. Some of the research has been directed at determining cardiopulmonary changes that occur during submaximal and maximal efforts while doing arm exercise. However, the amount of information available is scanty and indicates a need for continued work in this area.

Primarily, the arm ergometer has been utilized as the exercising machine. Some authors (Glaser et al., 1979; Wicks et al., 1977a, 1977b) compared arm ergometry to wheelchair ergometry and have reported that both methods produce similar results. However, some wheelchair ergometry studies used only nonhandicapped subjects (Stoboy et al., 1971; Glaser et al., 1979). It does seem, however, that either method is appropriate for cardiopulmonary training (Bar-Or and Zwiren, 1975; Glaser et al., 1979; Hildebrandt et al., 1970; Knutsson et al., 1973).

Knutsson et al. (1973) reported that upper limb impairment, in nonambulatory individuals, reduced the subject's ability to generate sufficient stress

*All the authors were at the University of Wisconsin-Madison when the study was conducted. 
upon the cardiopulmonary system so as to produce a training effect. This raises the question as to whether a water environment would allow nonambulatory individuals to do more work because of the bouyant effects of this medium. To date, there is a dearth of literature concerning cardiopulmonary responses of non-ambulatory individuals exercising within a water environment. The purpose of this study was to determine the cardiopulmonary performance of nonambulatory individuals during submaximal and maximal arm exercise both on land and in a water environment.

\section{Methods}

\section{Subjects}

Six handicapped $(\mathrm{H})$ and six nonhandicapped $(\mathrm{NH})$ individuals served as subjects. The mean age for each group was 33.3 years $(\mathrm{H})$ and 32.8 years $(\mathrm{NH})$, respectively. Five of the $\mathrm{H}$ group were wheelchair bound and one person needed crutches to ambulate. All the $\mathrm{H}$ subjects were unable to use their legs to generate enough stress to improve their cardiovascular efficiency. Table 1 gives pertinent demographic information about the subjects.

Table 1 Demographic information of subjects

\begin{tabular}{ccccll}
\hline Subject & Group $^{\mathrm{a}}$ & Sex & $\begin{array}{c}\text { Age } \\
\text { (years) }\end{array}$ & $\begin{array}{c}\text { WT } \\
(\mathrm{Kg})\end{array}$ & Disability \\
\hline JJ & H & M & 47 & $79 \cdot 4$ & Spinal Cord Injury, C7 \\
JB & H & M & 21 & $81 \cdot 7$ & Spinal Cord Injury, T8 \\
PL & H & M & 40 & $90 \cdot 7$ & Spinal Cord Injury, T12 \\
MC & H & M & 23 & 59 & Spinal Cord Injury, T12 \\
KM & H & F & 31 & $68 \cdot 9$ & Polio \\
VL & H & F & 37 & $44 \cdot 5$ & Polio \\
WA & NH & M & 29 & 70 & - \\
AH & NH & M & 29 & $66 \cdot 7$ & - \\
RW & NH & M & 33 & $63 \cdot 5$ & - \\
EL & NH & M & 42 & $72 \cdot 6$ & - \\
ID & NH & M & 39 & $79 \cdot 4$ & - \\
BC & NH & F & 25 & $68 \cdot 1$ & \\
\hline
\end{tabular}

${ }^{\mathrm{a}} \mathrm{H}=$ Handicapped

$\mathrm{NH}=$ Nonhandicapped

\section{Procedures}

Each subject engaged in two exercise stress test situations. One session was conducted on a land environment and one test was conducted in a water environment. All subjects engaged in the land test first. The protocol for each test was as follows:

1. Arm ergometry (Land). A Goddard electrically-braked bicycle ergometer was adapted to be used for arm ergometry work. Each subject was seated in front of the ergometer and the ergometer was adjusted so that the cranking pedals were a little less than shoulder height from the floor, and a distance from the body that was equal to the distance from the proximal side of the palm to the acromial process. The subjects were given a maximum exercise test using a discontinuous and progressive protocol.

Initially, resting measures were taken for a five minute period. This was 
followed by five minute work periods interspersed by five to ten minute rest periods. Increments of $100 \mathrm{kpm}$ were planned for each work period. If the subject's physical capacity did not allow $100 \mathrm{kpm}$ increments, and still provide four or five submaximal work outputs, then the amount of increment was adjusted. Thus, the increment of work intensity was determined according to the subject's performance. During the work period the cranking speed was $60 \mathrm{rpm}$ and the test was terminated when the subject could no longer maintain this cranking speed. Measurements were taken during the last minute of each workload.

An open circuit system was used to monitor ventilatory responses. Expired gas was collected into a chain-compensated gasometer with an attached potentiometer which measured frequency of respiration. Heart rate was measured with a standard three chest lead. A polygraph recorder was used to record frequency of respiration and heart rate (HR). Minute ventilation (VE, BTPS) and minute frequency of respiration (f) were calculated. A Beckman $E_{2}$ measured the oxygen concentration and a Beckman $\mathrm{LB}_{2}$ measured the carbon dioxide concentration of the expired gas. An oxygen uptake $\left(\dot{V O}_{2}\right.$ STPD) and $\mathrm{CO}_{2}$ production $\left(\dot{\mathrm{V} C O}{ }_{2}, \mathrm{STPD}\right)$ for each workload were calculated.

2. Tethered swimming (Water). Measurements were conducted in an environmentally controlled facility. A water tank $\left(12^{\prime} \times 6^{\prime} \times 5^{\prime}\right)$, filled to a water depth of four feet, with a tethered swimming apparatus was used for testing. The tethered apparatus (Fig. 1) included a metal bridge constructed over the tank on to which a movable bar was attached perpendicularly. The bar had a clip attached to the lower end. A nylon rope was attached to the bar and proceeded towards the back of the tank and passed over a pulley at the rear edge of the tank. The rope ran parallel to the water and was attached to weights at the back edge of the tank. The subject wore a nylon belt around his/her waist and the clip was attached to this belt. The water temperature was maintained at $30^{\circ} \mathrm{C}$.

The subjects wore goggles, a nose clip, and breathed through a one way snorkel

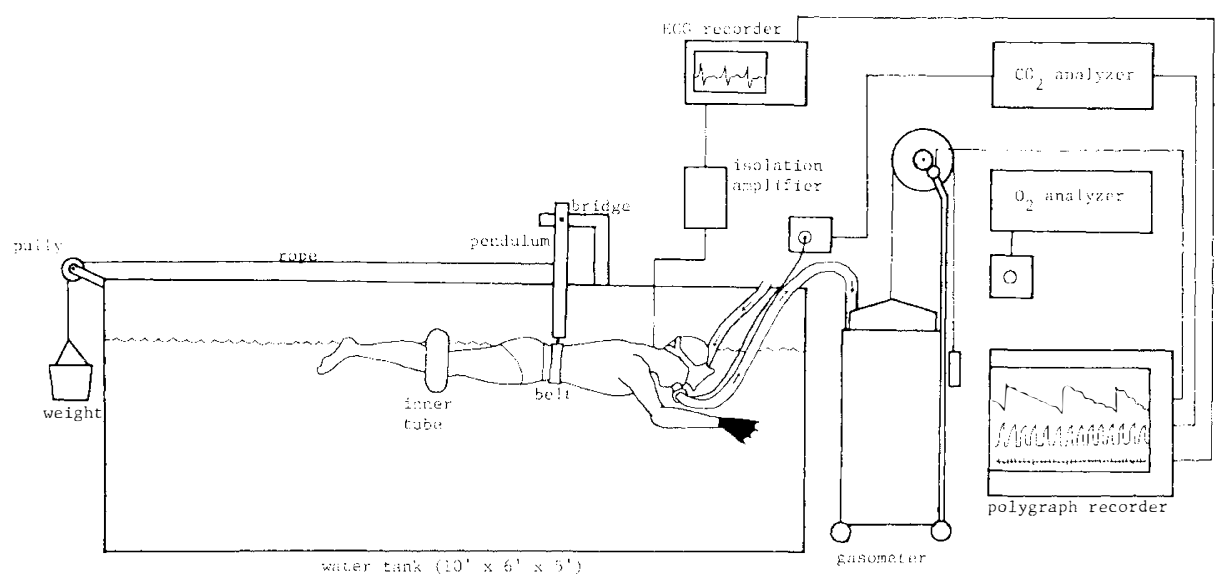

Figure 1. Attachment of the subject to the tethered mechanism in the water tank. 
with a large bore ( $1 \frac{1}{4}^{\prime \prime}$ inner diameter). The subjects swam using only the arms in a prone position. Both legs of the subject were kept floating by a rubber tube. Each subject used a pace that maintained the bar in a vertical position. Constant verbal feedback was given to the subject concerning the position of the bar (Fig. 1).

A five minute resting measurement was taken while the subjects floated in a prone position in the water. The protocol was discontinuous and progressive, with each workload lasting five minutes and each rest period being five to ten minutes long. The subjects continued until they were unable to do the work or maintain the bar in the vertical position. Measurements were taken the last minute of each workload. To calculate $\dot{\mathrm{VE}}, \dot{\mathrm{f}}, \mathrm{HR}, \dot{\mathrm{VO}}_{2}$ and $\dot{\mathrm{VCO}_{2}}$, the same procedure was employed that was utilised for the land test.

For statistical analysis, the $\dot{\mathrm{VE}}$ for a given $\mathrm{VO}_{2}$ was analysed using a nonlinear regression procedure. All other relationships were analysed by a multiple linear regression procedure.

\section{Results}

The physiological responses of the subjects to the exercise encountered in this study will be discussed in terms of ventilation, heart rate responses and oxygen uptakes. The environmental effects of water vs. land will also be discussed.

\section{Ventilation}

The $\mathrm{H}$ subjects had higher ventilatory outputs on land than in the water. Five out of six $\mathrm{H}$ subjects had higher minute ventilations ( $\dot{\mathrm{VE}}$ ) both at rest and during maximum efforts. Figure 2 shows the regression lines of $\dot{\mathrm{VE}}$ to a given $\dot{\mathrm{VO}}_{2}$ for the handicapped subjects. The estimated VE on land was consistently higher than for a water environment. As can be seen from the graph, both at rest and during exercise the standard deviations do not cross. This would tend to indicate that there is a significant difference between the regression lines of the estimated $\dot{V} E$. The $R$ values for the land and water environments were 90 and .95 , respectively. Figure 3 shows a higher estimated $f$ on land for the handicapped subjects ( $R$ values on land in the water are 63 and $\cdot 64$, respectively). This would, again, indicate that the handicapped subjects are expending more energy for breathing on land than in the water.

When compared to the $\mathrm{NH}$ control group, five $\mathrm{H}$ subjects were unable to attain the same level of VEmax as the majority of the $\mathrm{NH}$ group. However, both groups attained higher values on land than in water (Table 2). The $\mathrm{H}$ subjects, as a group, had higher $\dot{\mathrm{VE}} / \mathrm{V}_{2}$ ratios on land than did the $\mathrm{NH}$ group, but no general pattern was observed in a water environment (Table 2).

\section{Oxygen uptake}

Within the $\mathrm{H}$ group, the more disabled individuals (JB and $\mathrm{JJ}$ ) had a higher maximum $\dot{\mathrm{O}}_{2}$ in the water while the less disabled individuals (MC and PL) had a higher $\mathrm{V}_{2}$ max on land (Table 2). The two individuals with polio had similar $\dot{\mathrm{VO}}_{2}$ max values in both environments. The $\mathrm{NH}$ subjects generally had 


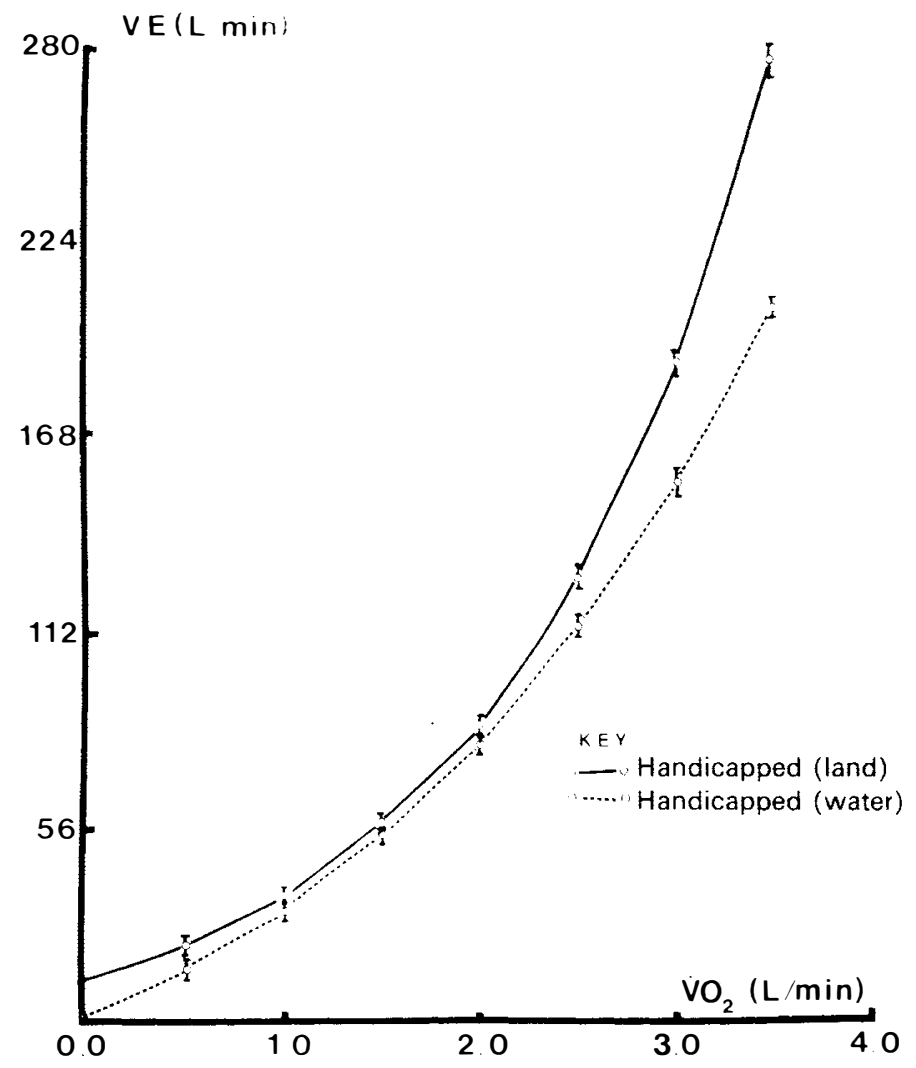

Figure 2. Regression lines of $\dot{\mathrm{VE}}$ to a given $\mathrm{VO}_{2}$ for the handicapped subjects in both environments.

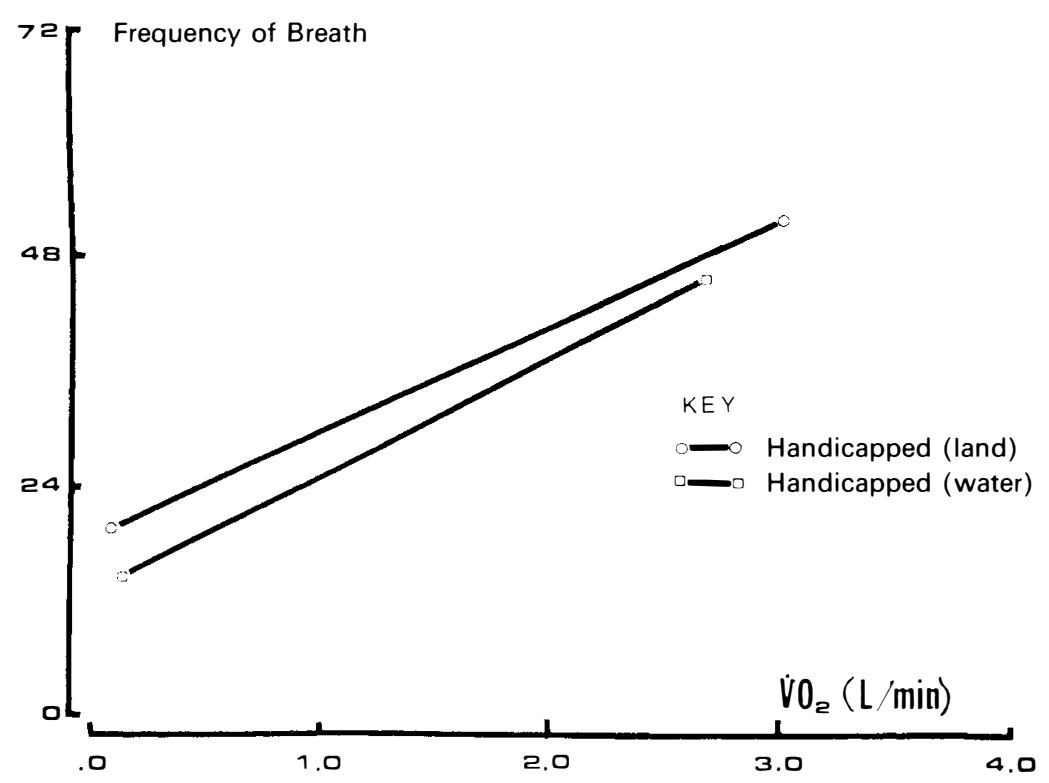

Figure 3. Regression lines for $\dot{\mathrm{f}}$ at a given $\mathrm{VO}_{2}$ for the handicapped subjects in both environments. 
Table 2 Maximal ventilation and oxygen uptake results to exercise for each subject

\begin{tabular}{|c|c|c|c|c|c|c|}
\hline & \multicolumn{2}{|c|}{$\dot{\mathrm{VE}}$} & \multicolumn{2}{|c|}{$\dot{\mathrm{VO}_{2}}$} & \multicolumn{2}{|c|}{$\dot{\mathrm{VE}} / \dot{\mathrm{VO}}_{2}$} \\
\hline & $\mathrm{L}$ & W & $\mathrm{L}$ & W & $\mathrm{L}$ & W \\
\hline JB & $65 \cdot 5$ & $71 \cdot 1$ & $20 \cdot 8$ & $22 \cdot 3$ & $38 \cdot 57$ & 38.99 \\
\hline $\mathrm{JJ}$ & $65 \cdot 5$ & $48 \cdot 2$ & $8 \cdot 8$ & $13 \cdot 3$ & 93.49 & $45 \cdot 67$ \\
\hline VL & $60 \cdot 5$ & $56 \cdot 7$ & $26 \cdot 6$ & $26 \cdot 6$ & $51 \cdot 14$ & $47 \cdot 94$ \\
\hline MC & $81 \cdot 9$ & $62 \cdot 8$ & 31.9 & $25 \cdot 5$ & $43 \cdot 48$ & $41 \cdot 69$ \\
\hline KM & 37.9 & $24 \cdot 9$ & $11 \cdot 0$ & $11 \cdot 0$ & $50 \cdot 19$ & $32 \cdot 81$ \\
\hline PL & $185 \cdot 9$ & $127 \cdot 6$ & $32 \cdot 7$ & $28 \cdot 7$ & $62 \cdot 78$ & $49 \cdot 04$ \\
\hline WA & 115.9 & $81 \cdot 0$ & $32 \cdot 1$ & $24 \cdot 4$ & $51 \cdot 56$ & $47 \cdot 46$ \\
\hline RW & $94 \cdot 3$ & $93 \cdot 3$ & 37.9 & $32 \cdot 3$ & $39 \cdot 16$ & $45 \cdot 46$ \\
\hline $\mathrm{AH}$ & $86 \cdot 5$ & $91 \cdot 4$ & $34 \cdot 4$ & $30 \cdot 1$ & $37 \cdot 69$ & $45 \cdot 47$ \\
\hline EL & $128 \cdot 1$ & 78.8 & $45 \cdot 6$ & $27 \cdot 8$ & $38 \cdot 74$ & 38.98 \\
\hline $\mathrm{BC}$ & $76 \cdot 1$ & $78 \cdot 8$ & $19 \cdot 3$ & $25 \cdot 5$ & 58.04 & $45 \cdot 37$ \\
\hline ID & $97 \cdot 8$ & $63 \cdot 8$ & $27 \cdot 9$ & $21 \cdot 4$ & $44 \cdot 13$ & $37 \cdot 54$ \\
\hline
\end{tabular}

higher $\dot{\mathrm{VO}}_{2} \max$ values than the $\mathrm{H}$ subjects. The $\dot{\mathrm{VO}}_{2}$ values of the two groups were more similar in the water environment than on the land environment (Table 2).

\section{Heart rate}

The $\mathrm{H}$ subjects displayed a marked bradycardia in the water environment. Table 3 shows the resting and maximum $\mathrm{HR}$ of each subject in both environments. It can be seen that all the $\mathrm{H}$ subjects had a lower resting $\mathrm{HR}$ and four $\mathrm{H}$ subjects had a lower maximum $H R$ in the water as compared to their results on land. Figure 4 shows the regression lines of $\mathrm{HR}$ to a given $\mathrm{VO}_{2}$ for both groups in each environment. The $\mathrm{H}$ subjects' estimated $\mathrm{HR}$ in the water environment is seen to be lower, both at rest and during exercise. The $\mathrm{R}$ values were $\cdot 71$ for the subjects on land, .79 for the $\mathrm{H}$ subjects in the water, .82 for the $\mathrm{NH}$ subjects on land and 86 for the $\mathrm{NH}$ subjects in the water.

Figure 4 also shows that in both environments the $\mathrm{H}$ subjects had a higher estimated heart rate at a given $\mathrm{VO}_{2}$ than the $\mathrm{NH}$ group. The regression lines

Table 3 Resting and maximal heart rates on land and in the water for each subject

\begin{tabular}{lrccc}
\hline & \multicolumn{2}{c}{ Land } & \multicolumn{2}{c}{ Water } \\
\cline { 2 - 3 } \cline { 4 - 5 } & Rest & Max & Rest & Max \\
\hline JJ & 84 & 186 & 68 & 166 \\
JB & 84 & 112 & 63 & 130 \\
VL & 77 & 186 & 62 & 182 \\
MC & 76 & 179 & 62 & 138 \\
KM & 108 & 156 & 82 & 141 \\
PL & 74 & 180 & 61 & 180 \\
& & & & \\
WA & 50 & 140 & 48 & 112 \\
RW & 46 & 160 & 55 & 162 \\
AH & 56 & 170 & 62 & 180 \\
EL & 64 & 164 & 58 & 138 \\
BC & 74 & 170 & 66 & 190 \\
ID & 70 & 183 & 86 & 151 \\
\hline
\end{tabular}




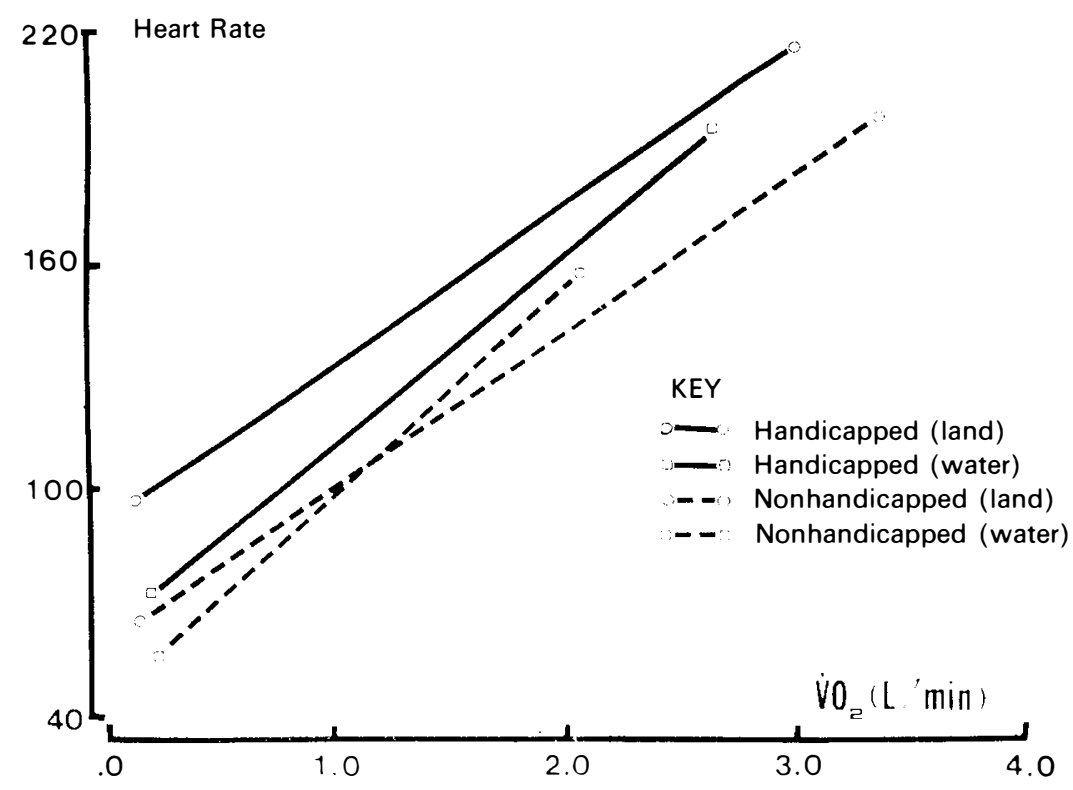

Figure 4. Regression lines for $\mathrm{HR}$ at a given $\dot{\mathrm{VO}}_{2}$ for all subjects in both environments.

on land for both groups can be seen in Figure 5. The graph indicates that the standard deviations at given $\dot{\mathrm{VO}}_{2}$ levels of each line do not cross. This would tend to indicate that there is a significant difference between the estimated HR of each group on land. Figure 6 shows that the $\mathrm{H}$ subjects had higher estimated $\mathrm{HR}$ for a given $\% \dot{\mathrm{VO}}_{2} \max$ in both environments. The difference was minimal in the water but more observable on land. The difference on land was reduced when the $\% \dot{\mathrm{VO}}_{2} \max$ went above 50 per cent. The $\mathrm{R}$ values on land and in the water for the $\mathrm{H}$ subjects were $\cdot 82$ and .91 and for the $\mathrm{NH}$ subjects were $\cdot 95$ and $\cdot 88$.

\section{Discussion}

The $\mathrm{H}$ subjects displayed increased ventilatory outputs, oxygen uptakes and heart rates when exercise stress was increased. This reaction to exercise was observed in both environments and is similar to the response observed in $\mathrm{NH}$ persons. This response, in the $\mathrm{H}$ subjects, to increased exercise stress has been reported by other authors (Brouha and Krobath, 1967; Carroll et al., 1979; Glaser et al., 1979; Knutsson et al., 1973; Voigt and Bahn, 1969).

All the measured variables indicated that the $\mathrm{H}$ subjects were less efficient in their work capacity when compared to NH subjects. This increased metabolic cost at a given intensity level was also reported by several authors (Barr-Or and Zwiren, 1975; Carroll et al., 1979).

The $\mathrm{H}$ subjects' lower $\dot{\mathrm{V} E}$ and $\dot{\mathrm{f}}$ to submaximal and maximal exercise in water (Figs. 2 and 3), as compared to land, was probably due to improved lung mechanics and ventilation to perfusion distribution. This was primarily due to the prone posture and the reduced effect of gravity seen in the water, which induces blood 


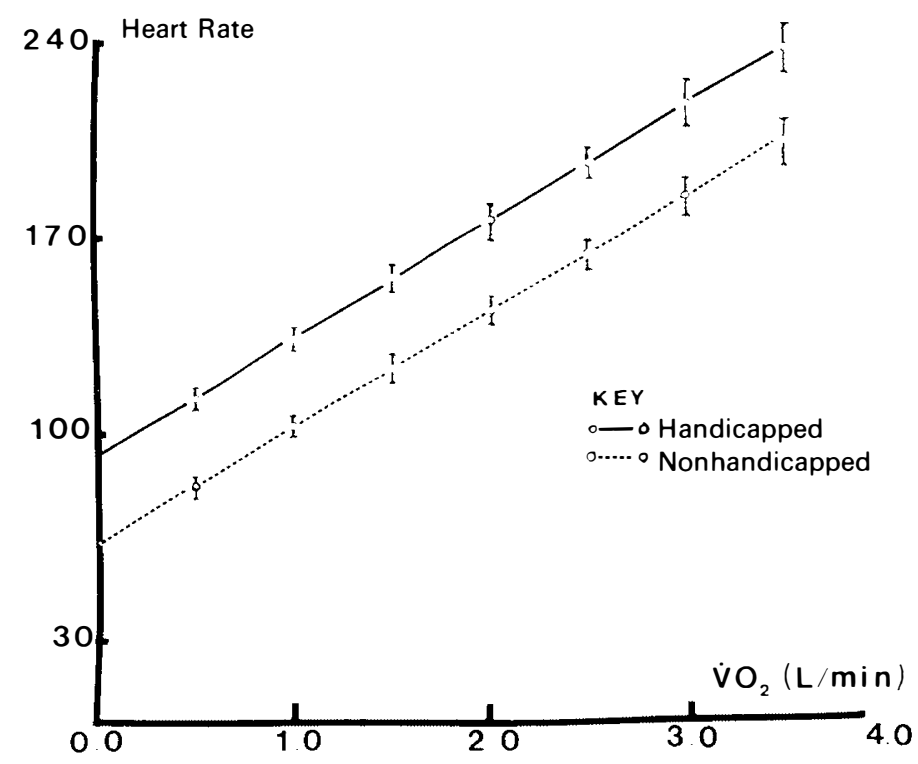

Figure 5. Regression lines for $\mathrm{HR}$ to a given $\mathrm{VO}_{2}$ for all subjects on land.

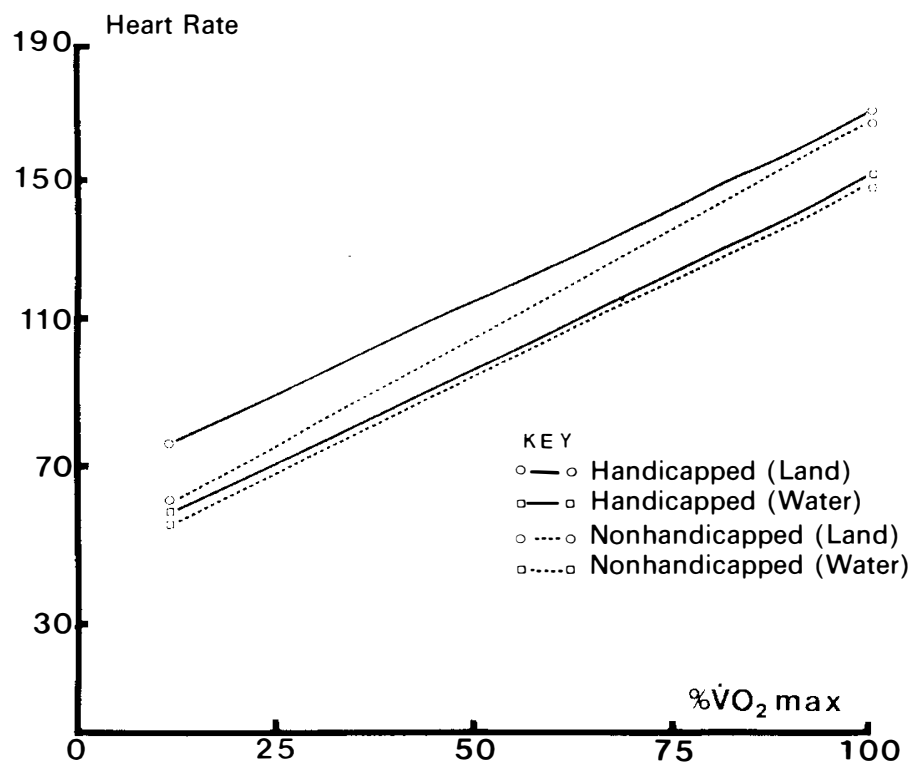

Figure 6. Regression lines for $\mathrm{HR}$ to a given $\% \mathrm{VO}_{2} \max$ for all subjects in both environments.

redistribution and probably better respiratory muscle performance. This improved ventilatory efficiency is reflected in the closer $\dot{\mathrm{VE}} / \mathrm{V}_{2}$ ratios observed between the $\mathrm{H}$ and $\mathrm{NH}$ subjects in the water as opposed to exercising 
on land (Table II). It is suggested that the $\mathrm{NH}$ subjects attained higher $\dot{V}$ Emax results because they were able to achieve higher $\dot{\mathrm{VO}}_{2} \mathrm{max}$ levels and thus needed greater ventilation.

A large improvement in venous return from the lower extremities may be the reason for the significant bradycardia observed in the $\mathrm{H}$ subjects when they exercised in the water. The improved venous return results from prone posture, the reduced effect of gravity and the slightly negative pressure breathing. The improved venous return increased the central blood pooling, which in turn would increase the stroke volume and reflexively slow the heart rate.

The improvement in stroke volume seemed to have the greater effect at low stress levels (Fig. 6). Apparently, when exercising on land, the reduced muscle tone and/or activity of the lower extremities did not produce sufficient venous return at the low stress levels to provide an adequate stroke volume to meet the body's oxygen demands without significantly increasing heart rates. Knutsson et al. (1973) reported that 50 per cent of his nonambulatory subjects had lower than expected hemoglobin counts and 65 per cent had lower than expected blood volumes. These factors may also account for the lower oxygen content per stroke volume for the $\mathrm{H}$ subjects, which would result in a higher heart rate per stress level.

Knutsson et al. (1973) stated that individuals with spinal cord injuries above T6 would have reduced vasomotor control and therefore they would have blocks on the normal heart adaptations to stress. He felt that they would only be able to attain maximum heart rates of approximately 100 to $130 \mathrm{bpm}$. In this study only one subject $(\mathrm{JJ})$ had a spinal cord injury above T6. He was able to attain maximum heart rates on land and in the water of 112 and $130 \mathrm{bpm}$, respectively. Another subject (JB) with an injury at T8 had maximum heart rates of 186 and $166 \mathrm{bpm}$ and a third subject (KM) who was a polio victim with some arm involvement had maximum heart rates of 156 and $141 \mathrm{bpm}$ on land and in water, respectively. Thus the data of this study seemed to confirm Knutsson's observation.

The improved results, seen in the ventilation and heart rate responses of the $\mathrm{H}$ subjects while exercising in the water, appears to have helped the more disabled subjects to achieve higher $\mathrm{VO}_{2}$ max levels in the water environment. The greater $\mathrm{VO}_{2}$ max and work capacity observed for the $\mathrm{NH}$ subjects was primarily due to three factors: 1) a greater active muscle mass which resulted in more oxygen being consumed, 2) better trunk stabilisation that allowed the muscles to do more work, 3) a better general fitness level for the $\mathrm{NH}$ subjects. Most likely, the reduced differences between the groups observed in the water were probably due to the fact that there was less need for trunk stabilisation and an increase in venous return for the $\mathrm{H}$ subjects. Bar-Or and Zwiren (1975) stated that during arm ergometry testing $\mathrm{NH}$ subjects use their legs and trunks to a greater extent. The authors believe this happened also with our subjects.

\section{Résumé}

Des exercises de tolérance ont été donnes sur le sol et dans l'eau à six handicappés et a six nonhandicappes. Les candidats ont exercé seulement avec leurs bras et leurs fonctions cardiopulmonaire ont été évalués. D'après les résultats observés de cette étude, il paraît que les paralysés ayant une mauvaise condition physique souffraient davantage de fatigue cardio- 
pulmonaire lorsqu'ils font de l'exercice dans l'eau. Ceux qui sont moins handicappés ont montrés les mêmes tendances que ceux qui sont non-handicappés (c'est-à-dire, pas de changement dans leurs tendances) et n'ont pas pour autant reçu les mêmes crédits que ceux qui sont très handicappés. L'environment aquatique semblait améliorer la circulation des veins, la production cardiaque et la ventilation pulmonaire qui facilite aux handicappés d'être plus compétent dans leurs exercices.

\section{Zusammenfassung}

Sechs behinderte und sechs nichtbehinderte Versuchsteilnehmer wurden an Land und im Wasser auf koerperliche Belastungsvertraeglichkeit untersucht. Die Teilnehmer benutzten dabei nur ihre Arme und wurden auf ihre kardio-pulmonale Leistung geprueft. Die Untersuchungsergebnisse wiesen darauf hin, dass nichtambulatorische Individuen mit verminderten Leistungsfaehigkeit einem staerkeren kardiopulmonalen Stress bei Leibesuebung im Wasser faehig waren. Die weniger stark behinderten Teilnehmer wiesen Merkmalsgruppierungen auf, welche den nichtbehinderten Teilnehmern aehnlich waren (d.h. keine bemerkbare Gruppierung) und zogen daher eventuell einen nicht so grossen Nutzen als die staerker behinderten. Leibesuebung im Wasser steigert anscheinend venoesen Ruecklauf, Herzleistung und Lungenventilation, welche den behinderten Teilnehmern zu groesseren Wirksamkeit bei Leibesuebung verhelfen.

\section{References}

BAR-OR O, ZWIREN L 1975 Maximal oxygen consumption test during arm exercise: reliability and validity. Journal of Applied Physiology 38:424-426.

Brouha L, KROBATH H 1967 Continuous recording of cardiac and respiratory functions in normal and handicapped persons. Human Factors 9:567-572.

Carroll J, Hagberg J, Brooke M, Shumate J 1979 Bicycle ergometry and gas exchange measurements in neuromuscular disease. Archives of Neurology 36:457-461.

Glaser R, Sawka M, Laubach L, Suryaprasad A 1979 Metabolic and cardiopulmonary responses to wheelchair and bicycle ergometry. Journal of Applied Phsyiology 46(6):1066-1070.

Hildebrandt G, Voight E, Bahn D, Berendes B, KROGER J 1970 Energy costs of propelling a wheelchair at various speeds: cardiac responses and effect on steering accuracy. Archives of Physical Medicine and Rehabilitation, 51:131-136

Knutsson E, Lewenhaupt-Olsson E, Thorsen M 1973 Physical work capacity and physical conditioning in paraplegic patients. Paraplegia 11:205-216.

StOBoy H, RICH B, LEE M 1971 Workload and energy expenditure during wheelchair propelling. Paraplegia 8:223-230.

VoIGHT E, BAHN D 1969 Metabolism and pulse rate in physically handicapped when propelling a wheelchair up an incline. Scandinavian Journal of Rehabilitative Medicine 1:101-106.

Wicks J, Head E, Oldridge M, Cameron B, Jones N 1977 Maximum oxygen uptake of wheelchair atheltes competing at the 1976 Olympiad for the Physically Disabled. Medicine, Science and Sports 9:58 abstract.

Wicks J, Lumburner L, Dinsdale S, Jones N 1977 The use of multistage exercise testing with wheelchair ergometry and arm cranking in subjects with spinal cord lesions. Paraplegia 15:252-261. 